\title{
Immunizations and Autism: A Review of the Literature
}

\author{
Asif Doja, Wendy Roberts
}

\begin{abstract}
Because of a temporal correlation between the first notable signs and symptoms of autism and the routine childhood vaccination schedule, many parents have become increasingly concerned regarding the possible etiologic role vaccines may play in the development of autism. In particular, some have suggested an association between the Measles-Mumps-Rubella vaccine and autism. Our literature review found very few studies supporting this theory, with the overwhelming majority showing no causal association between the Measles-Mumps-Rubella vaccine and autism. The vaccine preservative thimerosal has alternatively been hypothesized to have a possible causal role in autism. Again, no convincing evidence was found to support this claim, nor for the use of chelation therapy in autism. With decreasing uptake of immunizations in children and the inevitable occurrence of measles outbreaks, it is important that clinicians be aware of the literature concerning vaccinations and autism so that they may have informed discussions with parents and caregivers.
\end{abstract}

RÉSUMÉ: Immunisation et autisme : revue de la littérature. Plusieurs parents s'inquiètent que des vaccins puissent jouer un rôle étiologique dans le développement de l'autisme à cause d'une corrélation temporelle entre les premiers signes et symptômes décelables de l'autisme et le calendrier vaccinal. Une association entre le vaccin contre la rougeole, les oreillons et la rubéole et l'autisme a été suggérée. Cette revue de la littérature a retrouvé peu d'études à l'appui de cette théorie, la très grande majorité des études ne démontrant pas d'association entre ce vaccin et l'autisme. On a d'autre part émis l'hypothèse d'un lien causal possible entre le thimerosal, un agent de conservation, et l'autisme. Là non plus, nous n'avons pas trouvé de données convaincantes à l'appui de cette hypothèse ou du traitement par chélation dans l'autisme. Avec la diminution du taux d'immunisation chez les enfants et l'apparition inévitable d'épidémies de rougeole, il est important que les cliniciens soient au courant de la littérature portant sur la vaccination et l'autisme afin qu'ils puissent en discuter en connaissance de cause avec les parents et les soignants.

Can. J. Neurol. Sci. 2006; 33: 341-346

Autism is a neurodevelopmental disorder involving deficits in behaviour and cognition with onset in the early childhood years. It manifests with dysfunction in three key domains: impairments in socialization, impairments in verbal and non-verbal communication, and patterns of restricted and repetitive patterns of behaviours and interests. ${ }^{1}$ Recent evidence has shown an increase in the prevalence of autism with numbers as high as six in $1000 .^{2}$ This increase, despite being believed to be due to increased awareness of the disorder and broadening of the Diagnostic and Statistical Manual of Mental Disorders (DSM) IV diagnostic criteria to include diagnoses on the continuum of the autistic spectrum, ${ }^{3,4}$ has caused some to question whether an environmental factor may be responsible for the observed increase.

Because autism usually becomes apparent by 15-18 months of age, many parents believe the immunizations received at this time are causally associated. ${ }^{5}$ The Measles-Mumps-Rubella vaccine (MMR) has unquestionably received the most scrutiny, as it is first scheduled to be given during the same time interval -- between 12 and 18 months. ${ }^{6}$ Additionally, up to $1 / 3$ of patients with autism exhibit some form of regression ${ }^{7}$ usually reported in

From the Division of Neurology (AD), Children's Hospital of Eastern Ontario, Ottawa, ON, Canada; Division of Developmental Paediatrics (WR), The Hospital for Sick Children, Toronto, ON, Canada.

ReCEIVED JANUARY 25, 2006. ACCEPTED IN FinAl FORM June 27, 2006.

Reprint requests to: Asif Doja, Division of Neurology, Children's Hospital of Eastern Ontario, 401 Smyth Road, Ottawa, Ontario, K1H 8L1, Canada. 
the second year of life, again temporally correlating with the MMR vaccination.

The goal of this paper is to examine the evidence for a causal association between the MMR vaccine and autism. Thus literature will be reviewed regarding (1) the initial hypothesis of a causal link between the MMR vaccine and autism; (2) the epidemiological data regarding the correlation between MMR and autism; and (3) the controversy surrounding the ethylmercury containing additive thimerosal which has also been suggested to be an etiological factor in autism.

\section{ThE MMR VACCINE, AUTISM AND THE ASSOCIATION WITH GASTROINTESTINAL DISEASE}

The controversy surrounding the association between the MMR vaccine and autism began in 1998 with a paper published by AJ Wakefield and colleagues ${ }^{8}$ in The Lancet. He examined 12 children with a history of normal development followed by regression co-existing with gastrointestinal (GI) complaints. The various complaints noted included diarrhea, abdominal pain, bloating and food intolerance. Upon endoscopy, all 12 children were found to have abnormalities ranging from lymphoid nodular hyperplasia to aphthoid ulceration. Wakefield also stated that the onset of behavioural symptoms was correlated with the MMR vaccine in 8 of the 12 children. Wakefield had previously suggested a link between inflammatory bowel disease (IBD) and the MMR vaccine ${ }^{9}$ and commented on a possible link between the GI inflammation observed in the autistic population and the MMR vaccine.

Wakefield and colleagues ${ }^{10}$ subsequently published a further article that examined 60 children with various developmental disorders (ranging from autism to dyslexia) and symptoms including abdominal pain, diarrhea, constipation and bloating. He found that $93 \%$ had ileocolonic lymphoid nodular hypoplasia (as compared to $14.3 \%$ of controls), however, no direct link to the MMR vaccine is discussed in the article and the suggestion that measles virus may be causative is only alluded to.

Since then, Wakefield has been more vocal regarding the relationship between MMR and autism. Before an American Academy of Pediatrics committee, ${ }^{11}$ he proposed that changes in intestinal permeability may allow neurotoxic intestinal products to cross the blood-brain barrier, which may be particularly susceptible during early development. He suggested that the MMR vaccine, representing an atypical pattern of measles exposure, might cause an increased risk for intestinal infection which may in turn lead to developmental regression. He also stated that monovalent vaccines would have a decreased risk as opposed to the typical MMR vaccine due to a decreased challenge to a vulnerable immune system. He summarized by stating that ${ }^{11}$ ". . . . the widespread use of MMR immunization is a major determinant of the apparent increase in rates of autism".

There has, however, been a lack of evidence to support the claims that MMR is causally associated with autism. In addition, there is no convincing evidence that monovalent vaccines pose fewer challenges to the developing immune system. Wakefield's ${ }^{12}$ findings of measles virus RNA in bowel disease have been supported by one report ${ }^{13}$ which looked at autism in particular, but have not been substantiated by others, ${ }^{14,15}$ thus making it difficult to draw any conclusions regarding the association between measles virus and GI disease. One study showed evidence of altered measles immunity in children with autism, ${ }^{16}$ although these positive results have been called into question due to issues of cross-contamination, as well as the use of unsubstantiated and un-validated biochemical techniques. ${ }^{17}$

A severe blow to the autism-MMR hypothesis was dealt in a 2004 article in the Sunday Times. It stated that up to five of the patients in Wakefield's original study were involved in a lawsuit against vaccine manufacturers prior to their participation in the study. As well, it was stated that Wakefield received up to 55,000 British pounds to assist their case by finding evidence linking autism with the MMR vaccine. ${ }^{18}$ In March of 2004, ten of the original authors of the 1998 Lancet article issued a retraction of the "interpretation of their findings", ${ }^{19}$ in part due to these allegations of research misconduct by Wakefield. The authors emphasized that a causal link was not established in their 1998 paper but acknowledged that the possibility of such a link has since been raised, and that this may have had implications for public health on a global scale. They subsequently agreed to ". . . formally retract the interpretation placed upon the findings in this paper. .."

\section{EPIDEMIOLOGICAL EVIDENCE REFUTING A CAUSAL ASSOCIATION BETWEEN AUTISM AND THE MMR VACCINE}

The bulk of the evidence refuting a causal link between the MMR vaccine and autism has come from epidemiologic research. ${ }^{20}$ Most make use of health maintenance organizations or national databases to retrospectively examine evidence for a causal association.

The most compelling evidence for a lack of association comes from Madsen et $\mathrm{al}^{21}$ who performed a retrospective cohort study on 537,303 children born between 1991 and 1998 in Denmark using the Danish Civil Registration system. Madsen identified cohorts of children who had been vaccinated against MMR (440,655 children) and those who had not been $(96,648$ children). They found no increased risk of autistic disorder or autistic spectrum disorder in the vaccinated compared to the unvaccinated groups.

Taylor et $\mathrm{al}^{22}$ looked for any evidence of any changes in the incidence of autism or age at diagnosis of autism associated with the introduction of the MMR vaccine in the United Kingdom (UK) in 1988. They found an overall increase in the incidence of autism, unrelated to the MMR vaccine. They found no sudden increase or "step up" in the incidence of autism after the introduction of the vaccine, nor did they find a difference in age in diagnosis of autism between vaccinated and unvaccinated children. Developmental regression was not found to be clustered in the months after vaccination.

Similar time trend analyses by Kaye et $\mathrm{al}^{23}$ and Dales et $\mathrm{al}^{24}$ supported these findings. In particular Kaye also found an increase in the incidence of autism between 1988-1993 in the UK while the rate of vaccination remained the same. Dales' study reported an increase in the reports of children receiving services for autism spectrum disorders occurring in the late 1980's and 1990's, long after the MMR vaccine was introduced in the United States. A recent Japanese study ${ }^{25}$ found that in a population which was experiencing decreasing rates of MMR vaccination, the incidence of autism actually increased.

A matched case-control study by Smeeth et $\mathrm{al}^{26}$ also found that MMR vaccination was not associated with an increased risk 
of being diagnosed with a pervasive developmental disorder. Makela et $\mathrm{al}^{27}$ using a retrospective design looking at 535,544 children in Finland also found no clustering of hospitalizations for autistic disorders after MMR vaccination. There were also no reports of autistic children making hospital visits for inflammatory bowel disease.

Many other studies focused on whether a "new-variant" of autism exists, ${ }^{17}$ namely one which occurs after MMR vaccination and specifically shows regression and GI disturbance. Fombonne and Chakrabarti ${ }^{28}$ found no increase in the "regressive" form of autism before and after the introduction of MMR in the UK. The mean intervals from parental recognition of autistic symptoms were comparable in those with and without regression. They found no reports of inflammatory bowel disorder in children with autism and no association between developmental regression and GI symptoms. Another study, which reviewed 14 years of vaccine related adverse events in Finland, found that none of the children who developed GI disturbance after MMR vaccination went on to develop autism. ${ }^{29}$ This is supported by Black et $\mathrm{al}^{30}$ who found no evidence that children with autism were more likely to have GI disorders prior to the diagnosis of autism. Taylor ${ }^{31}$ also examined this issue and did not find an increase in the percentages of children with autism who had GI tract symptoms or developmental regression after the introduction of the MMR vaccine.

\section{Thimerosal, AUTISM AND THE ISSUE OF POSSIBLE MERCURY POISONING}

Thimerosal is an organic compound of ethyl mercury used as a preservative to prevent vaccine multi-dose vials from bacterial and fungal contamination. In 1998 the US Food and Drug administration reviewed thimerosal containing products and concluded that, theoretically, with the number of vaccines given in the first six months of life, the recommended Environmental Protection Agency (EPA) guidelines for mercury ingestion could be exceeded. . $^{3233}$ The Food and Drug administration recommended that manufacturers remove thimerosal as much as possible from vaccines. Since 2001, thimerosal present in amounts large enough to act as a preservative have been removed from all childhood vaccines except for a few influenza and hepatitis vaccines. ${ }^{34}$ In Canada, the most common childhood vaccines have been free from thimerosal since 1992. The only exception to this is the infant Hepatitis B vaccine which contains amounts of mercury well below most safety estimates. ${ }^{5,35}$

One must bear in mind however that these guidelines referred to methylmercury, not ethylmercury, and that inferring that one compound acts similarly to the other may not be entirely appropriate. ${ }^{36}$ As well, methylmercury is transported across the blood-brain barrier via an active transport system, whereas ethyl mercury is not. Thus methylmercury is far more likely to cause nervous system toxicity. ${ }^{37}$

Similar to the MMR-autism story, the controversy concerning a link between thimerosal and autism essentially began with a single article. This paper, published by Bernard et $\mathrm{al}^{38}$ in Medical Hypotheses, questioned whether autism is in fact a novel form of mercury poisoning. They suggest that certain features of methylmercury exposure and autism are similar, including clinical and biological traits.

As stated by Nelson and Bauman ${ }^{36}$ in their critique of the
Bernard article -- Bernard et al do not distinguish between typical and rare manifestations when comparing the clinical features of methylmercury poisoning to autism. The most common motor manifestations of mercury toxicity are ataxia, dysarthria and tremor, whereas in autism, the most common motor findings are sterotypies. As well, bilateral constriction of visual fields, while being characteristic in mercury poisoning, is not seen in autism. Early exposure to mercury usually leads to a small head size and microcephaly, whereas children with autism tend to have larger heads than the rest of the population. They also note that rates of autism did not increase after epidemics of mercury poisoning, such as the one occurring in the 1950's in Minimata, Japan. ${ }^{36}$

In a 2004 study by Ip et al, ${ }^{39}$ mercury levels were compared between autistic children and controls using a cross-sectional cohort design. The authors found no significant differences between hair and blood mercury levels between the two groups. These findings were in keeping with Pichichero et $\mathrm{al}^{40}$ who compared children exposed to thimerosal in vaccines to an unmatched control group who had never had thimerosal in vaccines. They found no elevation in blood mercury levels in either group. Additionally, Holmes et $\mathrm{al}^{41}$ looked at mercury levels in first baby haircuts in children with autism and in fact found levels to be lower in autistic patients as compared to controls. The authors however interpreted this as evidence of impaired excretion of mercury as opposed to evidence of toxicity.

A number of epidemiologic and ecologic studies have been conducted regarding the possible association between autism and thimerosal. ${ }^{32}$ One study by Geir and Geir, ${ }^{42}$ using the Vaccine Adverse Events Reporting System (VAERS) in the US, did show an increase in neurodevelopmental disorders (autism, mental retardation and speech disorders) after receipt of thimerosal containing vaccines. However, as Parker et $\mathrm{al}^{32}$ point out in their review of Geir's paper, there were multiple methodological concerns with the paper, seriously calling into question the validity of their conclusions. One problem is that the VAERS is a passive reporting, system; thus anyone can report an adverse event after vaccination, including health care providers, parents, patients etc. Another concern is that the diagnoses are never validated. Additionally, although certain adverse events, such as anaphylaxis, are mandatory by US law to report, autism and neurodevelopmental disorders are not. The authors also did not state how they abstracted symptom terms from the VAERS or how they dealt with diagnostic overlap or incomplete records. ${ }^{32}$ Parker et $\mathrm{al}^{32}$ point out that "reporting bias" may also have been present if parents were aware of a possible link between thimerosal exposure and autism and "diagnosing bias" might have caused health care providers to be more likely to diagnose autism in those exposed to thimerosal.

One study using computerized Health Maintenance Organization databases was unable to confirm or refute an association between thimerosal and neurodevelopmental disorders. ${ }^{43}$ Another cohort study again used the Danish Civil Registration System, ${ }^{44}$ but this time to look at the rate ratio of Autism in children who received thimerosal containing vaccines versus those containing thimerosal-free vaccines. The authors, found no association between thimerosal containing vaccines and autism, and additionally found no evidence of a dose 
response association. Andrews et $\mathrm{al}^{45}$ used a retrospective cohort methodology in the UK and found no increase in developmental disorders associated with the use of thimerosal containing vaccines. They did find an increased risk of tics with increasing thimerosal dose, although the authors felt this was a chance effect or the result of confounding factors.

Finally an ecological study ${ }^{46}$ looked at various time periods in Denmark: 1961-1970, when the cumulative ethylmercury dose was $200 \mu \mathrm{g}$ in the first 15 months of life; 1970-1992, when the dose was $125 \mu \mathrm{g}$ in the first 10 months of life; and 1992-2000 when vaccines did not contain thimerosal. They found the incidence of autism was stable until 1990 and then increased, most notably during the period when thimerosal was no longer used. Thus the authors concluded that there was no association between thimerosal containing vaccines and autism.

A few studies have found abnormalities in the biochemical pathways involved in the metabolism of methionine, homocysteine and glutathione. ${ }^{47}$ Some have extrapolated that these abnormalities may underlie the reason why some siblings of autistic children are at a greater risk for autism. Others have attempted to show that thimerosal can cause low levels of glutathione $e^{48}$ and can inhibit the activation of methionine by insulin-like growth factor-1 and dopamine. ${ }^{49}$ However these studies have significant flaws including using extremely high doses of thimerosal (much higher than would be found through vaccines), using an in vitro instead of in vivo model, and using a neuroblastoma cell line instead of using a cell line derived from the developing central nervous system.

Because glutathione has a role in eliminating toxic substances from the body, some believe that a deficiency could cause autistic children to have predisposition to ethylmecury toxicity from thimerosal. This is largely unfounded, as glutathione is a relatively weak mercury chelator and does not have a much greater affinity for mercury than the body tissues as a whole. Nevertheless, some parents and researchers have advocated using chelation therapy for children with autism. For example, EDTA, while widely used as chelation therapy in autistic patients, in fact has a low affinity for mercury and is poorly absorbed in the oral form. The two main agents that act as effective mercury chelators are DMPS (2,3-dimercaptopropane1-sulfonate) and DMSA (2,3-dimercaptosuccinic acid). DMSA is an approved and relatively safe treatment lead toxicity in children, while DMPS has potentially more toxicity. However DMSA is not without potential serious adverse reactions including rash, bone marrow suppression and liver toxicity. Some practioners have begun to use a transdermal preparation of DMSA to treat autisitc patients; however since DMSA is watersoluble, it does not dissolve well in water or oil and thus would likely not be absorbed well through the skin.

Based on the lack of evidence for mercury being a causative agent, the use of chelation therapy is not evidence-based. Even if mercury toxicity was the cause of autism, chelation therapy does not reverse the cerebral damage done by previous exposure, it only prevents further damage. There is currently no evidence for the value of chelation therapy in autism and thus evidence based recommendations would not support the use of chelation therapy in these patients. Indeed, some feel this treatment may in fact be unsafe. ${ }^{50}$ In August 2005, a five-year-old autistic child died after receiving chelation therapy. ${ }^{51}$

\section{CONCLUSIONS AND IMPLICATIONS}

The bulk of the evidence suggests no causal relationship between the MMR vaccine and autism, and Wakefield's initial hypothesis has been refuted by numerous well-designed studies. Additionally, no consistent link between gastrointestinal disorders, the MMR vaccine and autism has been shown.

Similarly, the lack of an association between thimerosal and autism has also been convincingly demonstrated. As well, since the use of thimerosal in vaccines in the United States is minimal and is even less of an issue with respect to Canadian vaccines, the argument against vaccination based on the grounds of "mercury poisoning" is not warranted. This is particularly true when one considers that the incidence of autism has continued to rise while the use of thimerosal has declined.

Statements and reviews by the Canadian Pediatric Society, ${ }^{3}$ the American Academy of Pediatrics, ${ }^{11}$ and the World Health Organization $^{52}$ have been published supporting the continued use of the MMR vaccine and agreeing that the evidence to date does not support an association between the vaccine and autism. As well, an independent review and the Institute of Medicine in the United States has concluded that neither the MMR vaccine nor thimerosal is associated with autism. ${ }^{53}$

Despite this, parents continue to have concerns regarding the safety of vaccines. In a 2000 survey, more than $50 \%$ of parents of autistic children felt that vaccines were the main causal factor in autism. ${ }^{11}$ There are numerous groups, largely made up of parents of autistic children, who strongly believe that vaccines were causative in their child's autism. They include Generation Rescue (www.generationrescue.org), SafeMinds (www. safeminds.org) and Moms against Mercury (www.moms againstmercury.org). The following is a statement by Moms against Mercury founder Amy Carson, from the organization's website, and represents a typical parent perspective:

"My son was born a healthy child. As time went on and the more he was vaccinated, the more he started to change. Not knowing that mercury was in vaccines until he was four years old, I had no idea what was truly wrong with him ... I was outraged that I was not told that the most powerful neurotoxin was going to be injected in my new born child. It has devastated and changed our lives forever. . . I am dedicated to advocating for safer and mercury free vaccines and helping to educate parents by raising awareness of the mercury and the other dangerous ingredients in our vaccines." 54

Decreased uptake of immunizations have resulted in an increase in wild measles outbreaks. These outbreaks can and do still occur in Canada, usually among non-immunized persons. ${ }^{55,56}$ In the United Kingdom, uptake of MMR vaccination fell from $92 \%$ in $1995-96$ to $82 \%$ in $2002-3^{57}$ and measles outbreaks have subsequently occurred. ${ }^{58}$

What can be done to reverse this dangerous trend? Firstly, health care practitioners must take parents' concerns seriously and be prepared to listen to their viewpoints. Presenting the evidence for safety as well as the risks of delaying vaccination seem to be the most effective strategies when informing parents. Health care providers can review the key points outlined in this article (Table) and consider giving caregivers previously published "Guides for Parents". 5 Many parents get their information from the internet, thus one should consider directing parents to the website of the Canadian Coalition for 
Immunization Awareness and Promotion (www.immunize.cpha. ca) or www.immunize.org, both of which contain links to various internet resources for parents regarding vaccine safety. Awareness and education should eventually help parents to be comfortable in making the best choices for their children in terms of giving routine vaccinations at suggested times.

\section{Table: Summary of Key Points Regarding Immunizations and Autism}

The incidence of autism has been increasing

There is no convincing biological evidence that the measles virus or the MMR vaccine is related to autism

Thimerosal has been absent from Canadian vaccines since 1992 (save for some influenza and hepatitis vaccines)

There is no convincing evidence that the ethylmercury found in thimerosal has an etiological role in autism

Chelation therapy is an unproven and potentially dangerous therapy for children with autism

\section{REFERENCES}

1. American Psychiatric Association. Diagnostic and statistical manual of mental disorders. 4th ed. Washington D.C: American Psychiatric Association; 1994.

2. Bryson SE, Smith IM. Epidemiology of autism: Prevalence, associated characteristics and implications for research and service delivery. Mental Retard Dev Disab Res Rev. 1998; 000:1-7.

3. Canadian Paediatric Society, Infectious Diseases and Immunization Committee. Measles-mumps-rubella vaccine and autistic spectrum disorder: a hypothesis only. Paediatr Child Health. 2001; 6:387-91.

4. Fombonne E. Is there an epidemic of autism? Pediatrics. 2001; 107:411-2.

5. Roberts W, Harford M. Immunization and children at risk for autism. Paediatr Child Health. 2002; 7:623-32.

6. American Academy of Pediatrics Committee on Infectious Diseases. Red Book. 26th ed. Elk Grove Village Il: American Academy of Pediatrics; 2003.

7. Filipek PA, Accardo JA, Baranek GT, Cook Jr. EH, Dawson G, Gordon B, et al. The screening and diagnosis of autistic spectrum disorders. J Aut Dev Dis. 1999; 29:439-84.

8. Wakefield AJ, Murch SH, Linnell AJ, Casson DM, Malik M, Berelowitz M, et al. Ileal-lymphoid-nodular hyperplasia, nonspecific colitis, and pervasive developmental disorder in children. Lancet. 1998; 351:637-41.

9. Thompson NP, Montgomery SM, Pounder RE, Wakefield AJ. Is measles vaccination a risk factor for inflammatory bowel disease? Lancet. 1995; 345:1071-4.

10. Wakefield AJ, Anthony A, Murch SH, Thomson M, Montgomery SM, Davies S, et al. Enterocolitis in children with developmental disorders. Am J Gastro. 2000; 95:2285-95.
11. Halsey N, Hyman S. Conference writing panel. Measles, Mumps and Rubella Vaccine and Autism Spectrum Disorder. Report from the New Challenges in Childhood Immunization Conference convened at Oak Brook, Illinois, June 12-13, 2001. Pediatrics. 2001; 107:1-23.

12. Wakefield AJ, Pittilo RM, Sim R, Cosby SL, Stephenson JR, Dhillon AP, et al. Evidence of persistent measles virus infection in Chron's disease. J Med Virol. 1993; 39:345-53.

13. Uhlman V, Martin CM, Shiels O, Pilkington L, Silva I, Killalea A, et al. Potential viral pathogenic mechanism for new variant inflammatory bowel disease. Mol Pathol. 2002; 55:84-90.

14. Afzal MA, Armitage E, Begley J, Bentley ML, Minor PD, Ghosh S et al. Absence of detectable measles virus genome sequence in inflammatory bowel disease tissues and peripheral blood lymphocytes. J Med Virol. 1998; 55:243-9.

15. Iizuka $M$, Itou $H$, Chiba $M$, Shirasaka $T$, Watanabe $S$, et al. The MMR question. Lancet. 2000; 356:160.

16. Singh VK, Lin SX, Newell E, Nelson C. Abnormal measles-mumpsrubella antibodies and CNS autoimmunity in children with autism. J Biomed Sci. 2002; 9: 359-64.

17. Davis R. MMR and autism: a report for the Global Advisory Committee on Vaccine Safety. Available from: http://www.who.int/vaccine_safety/topics/mmr/mmr_autism_ davis.pdf. [Cited: 2005 Aug 24].

18. Deer, Brian. "Revealed: MMR reseach scandal. The Sunday Times (London). $2004 \mathrm{Feb} 22$.

19. Murch SH, Anthony A, Casson DH, Malik M, Berelowitz M, Dhillon AP, et al. Retraction of an interpretation. Lancet. 2004; 363:750.

20. Wilson K, Mills E, Ross C, McGowan J, Jaddad A. Association of autistic spectrum disorder and the measles, mumps and rubella vaccine: a systematic review of current epidemiological evidence. Arch Pediatr Adolesc Med. 2003; 157:628-34.

21. Madsen KM, Hvid A, Vestergaard M, Schendel D, Wohlfahrt J Thornsen $\mathrm{P}$, et al. A population-based study of measles, mumps, and rubella vaccination and autism. N Engl J Med. 2002; 347:1477-82.

22. Taylor B, Miller E, Farringtom CP, Petropoulos MC, Favot-Mayaud I, Li J, et al. Autism and measles, mumps and rubella vaccine: no epidemiological evidence for a causal association. Lancet. 1999; 353:2026-29.

23. Kaye JA, Melero-Montes MM, Jick H. Mumps, measles and rubella vaccine and the incidence of autism recorded by general practioners: a time trend analysis. BMJ. 2001; 322:460-3.

24. Dales L, Hammer SJ, Smith NJ. Time trends in autism and MMR immunization coverage in California. JAMA. 2001; 286:1183-5.

25. Honda H, Shimizu Y, Rutter M. No effect of MMR withdrawal on the incidence of autism: a total population study. J Child Psych Psychol. 2005; 46:572-79.

26. Smeeth L, Cook C, Fombonne E, Heavey L, Rodrigues LC, Smith PG, et al. MMR vaccination and pervasive developmental disorders: a case-control study. Lancet. 2004; 364:963-9.

27. Makela A, Nuorti JP, Petola H. Neurologic disorders after measlesmumps-rubella vaccination. Pediatrics. 2002; 110:957-63.

28. Fombonne E, Chakrabart S. No evidence for a new variant of measlesmumps-rubella-induced autism. Pediatrics. 2001; 108:1-8.

29. Petola H, Patja A, Leinikki P, Valle M, Davidkin I, Paunio M. No evidence for measles, mumps, and rubella vaccine-associated inflammatory bowel disease or autism in a 14-year prospective study. Lancet. 1998; 351: 1327-8.

30. Black C, Kaye JA, Jick H. Relation of childhood gastrointestinal disorders to autism: nested case-control study using data from the UK General Practice Database. BMJ. 2002; 325:419-21.

31. Taylor B, Miller E, Lingam R, Andrews N, Simmons A, Stowe J. Measles, mumps, and rubella vaccination and bowel problems or developmental regression in children with autism: population study. BMJ. 2002; 324:393-6.

32. Parker SK, Schwartz B, Todd J, Pickering LK. Thimerosalcontaining vaccines and autistic spectrum disorder: a critical review of published original data. Pediatrics. 2004; 114:793-804. 
33. US Environmental Protection Agency Mercury study report to congress: volume IV: an assessment of exposure to mercury in the United States. Available from: www.epa.gov/mercury. [Cited: 2005 Aug 24].

34. Food and Drug Administration. Thimerosal in vaccines. Available from http://www.fda.gov/cber/vaccine/thimerosal.htm. [Cited: 2005 Aug 24].

35. Health Canada. Exposure to thimerosal in vaccines used in Canadian infant immunization programs with respect to risk of neurodevelopmental disorders. Can Commun Dis Rep 2002; 28:28-69.

36. Nelson KB, Bauman ML. Thimerosal and autism? Pediatrics. 2003; 111: 674-9.

37. Kerper LE, Ballagtori N, Clarkson TW. Methylmercury transport across the blood-brain barrier by an amino acid carrier. Am J Physiol. 1992;262:R761-5.

38. Bernard S, Enayati A, Redwood L, Roger H, Binstock T. Autism: a novel form of mercury poisoning. Med Hypotheses. 2001; 56:462-71.

39. Ip P, Wong V, Ho M, Lee J, Wong W. Mercury exposure in children with autistic spectrum disorder: case-control study. J Child Neurol. 2004; 19:431-4.

40. Pichichero ME, Cernichiari E, Lopreiato J, Treanor J. Mercury concentrations and metabolism in infants receiving vaccines containing thimerosall: a descriptive study. Lancet. 2002; 360:1737-41.

41. Holmes AS, Blaxill MF, Haley BE. Reduced levels of mercury in first baby haircuts of autistic children. Int J Toxicol. 2003; 22:277-85.

42. Geier MR, Geier DA. Neurodevelopmental disorders after thimerosal-containing vaccines: a brief communication. Exp Biol Med. 2003; 228:660-4.

43. Verstraeten T, Davis RL, DeStefano F, Lieu TA, Rhodes PH, Black $\mathrm{SB}$, et al. Safety of thimerosal-containing vaccines: a two-phased study of computerized health maintenance organization databases. Pediatrics. 2003; 112:1039-48.

44. Hviid A, Stellfeld M, Wohlfahrt J, Melbye M. Association between thimerosal-containing vaccines and autism. JAMA. 2003; 290:1763-6.

45. Andrews N, Miller E, Grant A, Stowe J, Osborne V, Taylor B. Thimerosal exposure in infants and developmental disorders: a retrospective cohort study in the United Kingdom does not support a causal association. Pediatrics. 2004; 114:584-91.
46. Madsen K, Lauritsen M, Pedersen C, Thorsen P, Plesner AM, Anderson PH, et al. Thimerosal and the occurrence of autism? Negative ecological evidence from Danish population-based data. Pediatrics. 2003; 112:604-6.

47. James SJ, Cutler P, Melnyk S, Jernigan S, Janak L, Gaylor DW, et al. Metabolic biomarkers of increased oxidative stress and impaired methylation capacity in children with autism. Am J Clin Nutr. 2004; 80:1611-7.

48. James SJ, Slikker W, Melnyk S, New E, Pogribna M, Jernigan S. Thimerosal neurotoxicity is associated with glutathione depletion: protection with glutathione precursors. Neurotoxicology. 2005; 26:1-8.

49. Waly M, Olteanu H, Banerjee R, Choi SW, Mason JB, Parker BS, et al. Activation of methionine synthase by insulin-like growth factor-1 and dopamine: a target for neurodevelopmental toxins and thimerosal. Mol Psych. 2004; 1-13.

50. Shannon M, Levy S, Sandler A. Chelation therapy neither safe nor effective as autism treatment. AAP news. 2001:63.

51. The Times. Autistic boy, 5, dies after US therapy. August 26, 2005. Available from:(http://www.timesonline.co.uk/article/0,,2-1751 753,00.html) Cited: October 12, 2005.

52. World Health Organization. Global Advisory Committee on Vaccine Safety, 16-17 December 2002: MMR and autism. Weekly Epidemiological Record Available from:http://www.who.int/ wer/2003/en/wer7804.pdf [Cited: 2005 Aug 24].

53. Moms Against Mercury. Available from: http://www.momsagainst mercury.org/aboutus.htm. [Cited: 2006 May 2].

54. Institute of Medicine of the National Academies. Immunization safety review: Vaccines and autism. Available from http://www.iom.edu/report.asp?id=20155. [Cited: 2005 Aug 24].

55. Public Health Agency of Canada. Disease information measles Available from: http://www.phac-aspc.gc.ca/tmp-pmv/info/ measles_e.html. [Cited: 2005 Aug 24].

56. Public Health Agency of Canada. Measles Available from:http://www.phac-aspc.gc.ca/dird-dimr/vpdmev/measles_e.html. [Cited: 2005 Aug 24].

57. Department of Health. Statistical bulletin. NHS Immunization Statistics, England. Available from: http://www.dh.gov.uk/ PublicationsAndStatistics/Statistics/StatisticalWorkAreas/Statisti calHealthCare/StatisticalHealthCareArticle/fs/en?CONTENT_I $\mathrm{D}=4086491$ \&chk=LUyYGS. [Cited: 2005 Aug 24].

58. Jansen VA, Stollenwerk N, Jensen HJ, Ramsay Me, Edmunds WJ, Rhodes CJ. Measles outbreaks in populations with declining vaccine uptake. Science. 2003; 301:804. 